\title{
Two-pore domain potassium channels enable action potential generation in the absence of voltage-gated potassium channels
}

\author{
Georgina MacKenzie • Nicholas P. Franks • \\ Stephen G. Brickley
}

Received: 29 August 2014 /Revised: 13 November 2014 / Accepted: 21 November 2014 / Published online: 9 December 2014

(C) The Author(s) 2014. This article is published with open access at Springerlink.com

\begin{abstract}
In this study, we explored the possibility that two-pore domain potassium $\left(\mathrm{K}_{2 \mathrm{P}}\right)$ channels are sufficient to support action potential (AP) generation in the absence of conventional voltage-gated potassium $\left(\mathrm{K}_{\mathrm{V}}\right)$ channels. Hodgkin-Huxley parameters were used to mimic the presence of voltage-gated sodium $\left(\mathrm{Na}_{\mathrm{V}}\right)$ channels in HEK-293 cells. Recombinant expression of either TREK-1 or TASK-3 channels was then used to generate a hyperpolarised resting membrane potential (RMP) leading to the characteristic non-linear current-voltage relationship expected of a $\mathrm{K}_{2 \mathrm{P}}$-mediated conductance. During conductance simulation experiments, both TASK-3 and TREK-1 channels were able to repolarise the membrane once AP threshold was reached, and at physiologically relevant current densities, this $\mathrm{K}_{2 \mathrm{P}}$-mediated conductance supported sustained AP firing. Moreover, the magnitude of the conductance correlated with the speed of the AP rise in a manner predicted from our computational studies. We discuss the physiological impact of axonal $\mathrm{K}_{2 \mathrm{P}}$ channels and speculate on the possible clinical relevance of $\mathrm{K}_{2 \mathrm{P}}$ channel modulation when considering the actions of general and local anaesthetics.
\end{abstract}

Keywords Action potential $\cdot$ Potassium channels . Conductance simulation

G. MacKenzie

Department of Neuroscience, Tufts University School of Medicine,

136 Harrison Avenue, Boston, MA 02111, USA

N. P. Franks $\cdot$ S. G. Brickley $(\bowtie)$

Biophysics Section, Department of Life Sciences, Imperial College

London, South Kensington Campus, London, UK

e-mail: s.brickley@imperial.ac.uk

\section{Introduction}

Introduction of the Hodgkin-Huxley model [25] of action potential (AP) generation has been followed by an impressive functional and molecular characterisation of the diverse array of voltage-dependent conductances responsible for AP generation in the peripheral and central nervous system [6]. In contrast, the passive membrane leak that is a component of all HodgkinHuxley-based AP models has received relatively little direct attention. However, in a number of cell types, the two-pore domain potassium $\left(\mathrm{K}_{2 \mathrm{P}}\right)$ channel family has been identified as a key determinant of the membranes resting potassium permeability $[17,22,36]$. The increased potassium permeability imparted by $\mathrm{K}_{2 \mathrm{P}}$ channel expression leads to an increased input conductance and hyperpolarised resting membrane potential (RMP). In addition, the current-voltage relationship of the potassium leak conductance deviates significantly from a linear ohmic leak due to the asymmetrical distribution of potassium ions across the membrane $[14,21,26]$. The functional significance of this non-linear behaviour is not often considered. In cerebellar granule neurons (CGNs), this open rectification has been shown to influence the voltage-dependence of the input conductance $[9,10,12]$, and genetic ablation of specific $\mathrm{K}_{2 \mathrm{P}}$ channels (namely TASK-3 or KNCK9) from CGNs lead to a striking phenotype. The APs generated in CGNs from TASK-3 knockout mice are significantly broader and smaller [9]. Similar phenotypes have also been observed after genetic ablation or inhibition or $\mathrm{K}_{2 \mathrm{P}}$ channels in other neuronal subtypes [23] and in cardiac tissue (for a recent review see [43]). Slowing of both the AP upstroke and the repolarisation phase can be explained by changes in the membrane time constant, and this largely overlooked functional consequence of $\mathrm{K}_{2 \mathrm{P}}$ channel expression could have wider implications for AP generation in the central and peripheral nervous system. 
In this study, we tested the possibility that $\mathrm{K}_{2 \mathrm{P}}$ channels could both hyperpolarise the RMP and enable rapid AP repolarisation in the absence of $\mathrm{K}_{\mathrm{V}}$ channels. The simulation data shown in Fig. 1a included voltage-gated sodium currents $\left(I_{\mathrm{VGSC}}\right)$ that were based upon the Hodgkin-Huxley set of equations. As shown in Fig. 1b, we compared APs generated in the presence of either a linear leak $\left(I_{\Omega \text {-leak }}\right)$ based upon a simple Ohmic behaviour or a non-linear leak $\left(I_{\mathrm{GHK}-\text { leak }}\right)$ based upon the Goldman-Hodgkin-Katz (GHK) model to mimic the non-linear leak that is known to be generated by $\mathrm{K}_{2 \mathrm{P}}$ channels (see Brickley et al. [9]). Both the $I_{\Omega \text {-leak }}$ and the $I_{\mathrm{GHK}-\text { leak }}$ models reversed polarity at an equilibrium potential of $-98 \mathrm{mV}$ to mimic the presence of a potassium permeability, and the conductance magnitude was chosen to generate RMPs of $-60,-70$, and $-80 \mathrm{mV}$. The synaptic-like waveforms $\left(I_{\text {EPSC }}\right)$ shown in Fig. 1c were constructed from double exponential functions and were used to depolarise the RMP to AP threshold. It is clear from the simulation data presented in Fig. 1d that the hyperpolarisation provided by a potassium leak conductance was sufficient to repolarise the AP in the absence of voltage-gated potassium channels. Moreover, as $I_{\mathrm{GHK}-\text { leak }}$ increased so the AP duration got briefer due to the faster membrane time constant associated with the increased non-linear leak. As shown in Fig. 1e, f and a $I_{\mathrm{GHK}-\text { leak }}$ that

Fig. 1 Simulations to compare the influence of linear versus non-linear leak conductance relationships on AP repolarisation. a Properties of the voltage-gated sodium current $\left(I_{\mathrm{VGSC}}\right)$ used for simulation studies and dynamic-clamp experiments. The voltage and time-dependent conductance changes are plotted for simulations involving voltage steps from -40 to $0 \mathrm{mV}$ in $5-\mathrm{mV}$ increments. The voltage-dependence of ${ }^{\tau}$ decay for $I_{\mathrm{VGSC}}$ is also plotted. $\mathbf{b}$ The current-voltage relationships generated by the linear $\left(I \Omega_{\text {-leak }}\right)$ and the non-linear potassium leak conductance $\left(I_{\mathrm{GHK}}\right.$ leak) that generated RMPs of $-60 \mathrm{mV}$ (red line),$-70 \mathrm{mV}$ (grey line) and $-80 \mathrm{mV}$ (black line) are shown. The value of the linear leak conductance was $3.2 \mathrm{nS}$ for $-60 \mathrm{mV}, 4.9 \mathrm{nS}$ for $-70 \mathrm{mV}$ and $8.8 \mathrm{nS}$ for $-80 \mathrm{mV}$. The values of the GHK leak conductance at the minimum membrane potential (i.e. close to the RMP) was $0.65 \mathrm{nS}$ at $-60 \mathrm{mV}, 0.85 \mathrm{nS}$ at $-70 \mathrm{mV}$ and $1.8 \mathrm{nS}$ at $-80 \mathrm{mV}$ c Superimposed synaptic currents $\left(I_{\mathrm{EPSC}}\right)$ that were generated by double exponential functions with peak conductance values ranging from 0.5 to $10 \mathrm{nS}$. d The membrane voltage that resulted from summation of the currents generated by the conductance changes shown in $\mathbf{a}, \mathbf{b}$ and $\mathbf{c}$ as well as the capacitive current generated by the voltage change. The superimposed voltage records were generated using the $I_{\text {GHK-leak }}$ that resulted in an RMP of $-70 \mathrm{mV}$. e Representative examples of voltage simulations comparing the linear $\left(I \Omega_{\text {-leak }}\right)$ and the non-linear $\left(I_{\mathrm{GHK}-\text { leak }}\right)$ leak conductance. APs are generated at all values of $I_{\text {GHK-leak }}$ that fully repolarise back to the RMP. However, the lowest conductance value of $I \Omega_{\text {-leak }}$ that resulted in an RMP of $-60 \mathrm{mV}$ was insufficient to fully repolarise the RMP following stimulation by a 2-nS EPSC as shown by the trace indicated with a red circle. $\boldsymbol{F}$, Plots of AP repolarisation for all simulations indicating the linear $\left(I \Omega_{-l e a k}\right)$ and nonlinear $\left(I_{\mathrm{GHK}-\text { leak }}\right)$ leak that was capable of repolarisation the AP. The only condition where this was not possible was at an $I \Omega_{\text {-leak }}$ resulting in an RMP of $-60 \mathrm{mV}$. In this scenario, AP repolarisation was incomplete after the first EPSC of $2 \mathrm{nS}$, and no subsequent APs could be generated. This was in stark contrast to the $I_{\text {GHK-leak }}$ that resulted in an RMP of $-60 \mathrm{mV}$ that was always sufficient to repolarise the AP generates RMPs between $-70 \mathrm{~V}$ and $-80 \mathrm{mV}$ is sufficient to repolarise the membrane potential during an $\mathrm{AP}$, but an $I_{\Omega \text {-leak }}$ that generates an RMP of only $-60 \mathrm{mV}$ was not able to repolarise the AP. This computational data highlight the utility of a non-linear leak conductance of the type generated by $\mathrm{K}_{2 \mathrm{P}}$ channel expression.
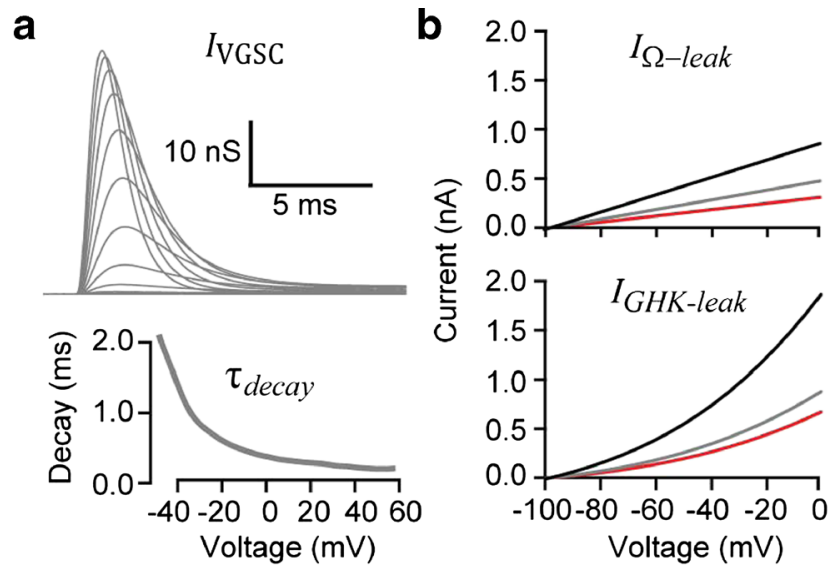

C
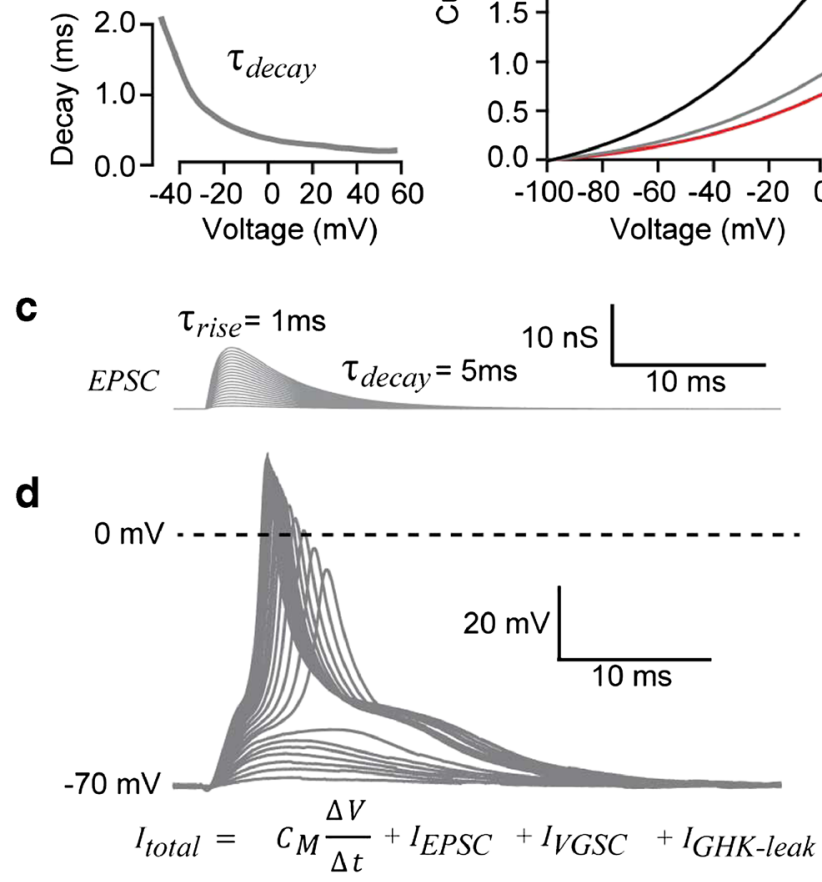

e

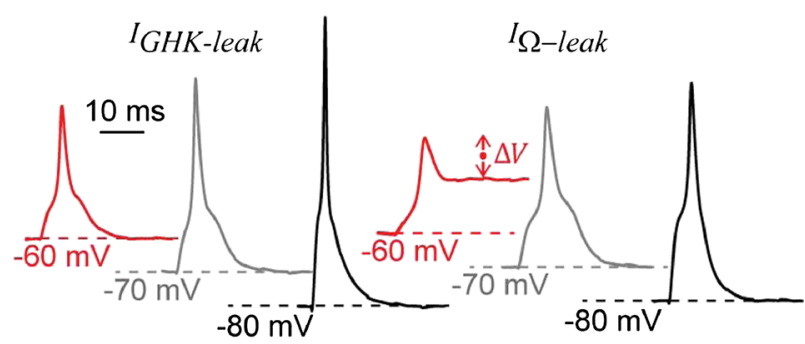

f

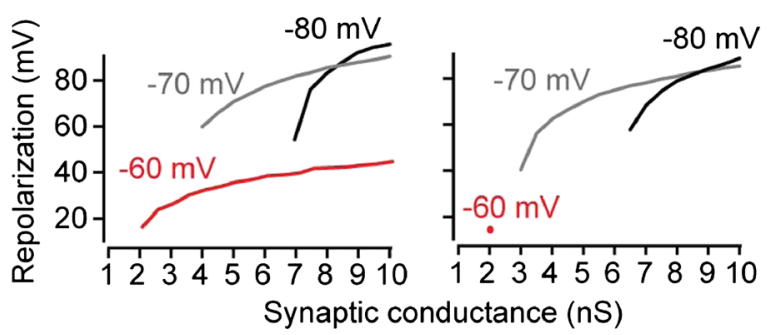


Informed by these simulations, we went on to explore experimentally the ability of $\mathrm{K}_{2 \mathrm{P}}$ channels to repolarise the AP in the absence of $\mathrm{K}_{\mathrm{V}}$ channels by using a dynamic-clamp procedure to mimic the presence of a sodium conductance in HEK-293 cells that were expressing the recombinant $\mathrm{K}_{2 \mathrm{P}}$ channels TREK-1 and TASK-3. In this way, we were able to demonstrate that $K_{2 P}$ channel expression alone was sufficient to generate APs, following $\mathrm{Na}_{\mathrm{V}}$ activation/inactivation, in the absence of $\mathrm{K}_{\mathrm{V}}$ channels. These experiments also demonstrated that, over a physiologically relevant range, AP shape could be altered by the potassium leak due to changes in the membrane time constant. The resistive shunt associated with a physiological $\mathrm{K}_{2 \mathrm{P}}$-mediated conductance did not negate AP generation but merely altered the current required to reach this threshold voltage. We went on to examine the consequence of enhancing the $\mathrm{K}_{2 \mathrm{P}}$-mediated leak conductance further with the volatile anaesthetic halothane. Once again AP attenuation was not observed at clinically relevant concentrations of halothane, but the enhancement of the $\mathrm{K}_{2 \mathrm{P}}$-mediated leak conductance resulted in a faster membrane time constant and therefore briefer APs. This hybrid simulation/expression approach demonstrates how AP properties could be influenced by $\mathrm{K}_{2 \mathrm{P}}$ channel expression in the central and peripheral nervous system.

\section{Methods}

\section{Cell culture and transfection}

Modified HEK-293 cells (tsA-201) were grown as monolayers in humidified $\left(95 \% \mathrm{O}_{2}, 5 \% \mathrm{CO}_{2}\right)$ incubators at $37{ }^{\circ} \mathrm{C}$. Upon reaching suitable confluency, cells were transferred to poly-D-lysine-coated glass cover slips for transfection using a transient calcium phosphate procedure with two separate plasmid DNA constructs encoding mouse TASK-3 $(0.2 \mu \mathrm{g} / \mu \mathrm{l}$ of TASK-3 DNA; [1]), human TREK-1 $(0.5 \mu \mathrm{g} / \mu \mathrm{l}$ of TREK-1 DNA) and Green Fluorescent Protein $(0.5 \mu \mathrm{g} / \mu \mathrm{l}$ of GFP DNA). Newly transfected cells were transferred from the laminar flow hood to a $37{ }^{\circ} \mathrm{C}, 97 \% \mathrm{O}_{2}$, and $3 \% \mathrm{CO}_{2}$ incubator for $16-18 \mathrm{~h}$. The transfection mixture was removed; the cells washed twice in phosphate buffered saline and fresh culture medium applied before plates were returned to the incubator for a further $24 \mathrm{~h}$ prior to electrophysiological recording.

\section{Electrophysiology}

Whole-cell recordings were made using either an Axopatch 200B amplifier or a Multiclamp 700B (Molecular Devices;
Foster City, CA) run via a National Instruments digitization board (PCI-6052E; National Instruments, Austin, Texas) linked to a dedicated PC. All experiments were performed at room temperature $\left(22-23{ }^{\circ} \mathrm{C}\right)$, and the pipette solution contained (in mM) $120 \mathrm{KCH}_{3} \mathrm{SO}_{4} ; 4 \mathrm{NaCl} ; 1 \mathrm{CaCl}_{2} ; 1$ $\mathrm{MgCl}_{2} ; 10$ HEPES; 5 EGTA; $3 \mathrm{Mg}$-ATP; and $0.3 \mathrm{Na}$-GTP (adjusted to $\mathrm{pH} 7.3$ with $\mathrm{KOH}$ ). Data acquisition and analysis were performed using WINWCP (version 3.3.3) kindly provided by John Dempster (CJohn Dempster; University of Strathclyde, UK). Voltage recordings were passed through a $2-\mathrm{kHz},-3-\mathrm{dB}, 8$-pole Bessel filter before digitization at a rate of $20 \mathrm{kHz}$. The blocking action of tetraethylammonium (TEA) on the endogenous voltage-gated potassium conductance was calculated from the steady-state current measured during standard voltage-step protocols. The TEA inhibition curve was calculated using a modified Hill equation. The potassium conductance $\left(G_{\mathrm{K}}\right)$ was calculated from the steady-state current $\left(I_{\mathrm{ss}}\right)$ recorded at a holding potential $\left(V_{\mathrm{h}}\right)$ of $-60 \mathrm{mV}$ using the potassium equilibrium potential $\left(E_{\mathrm{K}}\right)$ to estimate the driving force according to the relationship $G_{\mathrm{K}}=I_{\mathrm{ss}} /\left(V_{\mathrm{h}}-E_{\mathrm{K}}\right)$. The relationship between $G_{\mathrm{K}}$ and the RMP was adequately described by a single exponential function of the form $y=$ $A^{*} \exp ^{(-x / \tau)}+y_{\text {asymptote. }}$ The dynamic-clamp was implemented in a Labview 7.2 (National Instruments) software environment following adaptation of the original G-clamp software developed by Paul Kullmann [33]. A dynamically variable current was injected using a patch-clamp amplifier (interfaced to a slave computer via a National Instruments PCI-6052E DAQ board, Austin, Texas). To make use of the computers' full bandwidth, the slave computer was running embedded software controlled by a second master PC via an Ethernet connection. Dynamic-clamp simulation experiments were also implemented within Signal version 5 (Cambridge Electronic Design; Cambridge, UK) running a Multiclamp 700B (Molecular Devices; Foster City, CA) via a CED 1401 plus mk2 (Cambridge Electronic Design; Cambridge, UK).

Simulation of ionic conductance changes

The presence of a voltage-gated sodium conductance was based upon modified Hodgkin-Huxley equations:

For the activation gate $(m)$

$$
\begin{aligned}
& \alpha_{m}=\frac{0.36(V+33)}{1-e^{\frac{(-V-33)}{3}}} \\
& \beta_{m}=\frac{-2(V+42)}{1-e^{\frac{(V+42)}{20}}}
\end{aligned}
$$

$m=m+\left(\frac{d t}{10}\right)\left(\alpha_{m}-m\left(\alpha_{m}+\beta_{m}\right)\right)$ 
For the inactivation gate $(h)$

$\alpha_{h}=\frac{-0.1(V+55)}{1-e^{-\frac{V+55}{6}}}$

$\beta_{h}=\frac{0.45}{1+e^{\frac{(-V)}{10}}}$

$h=h+\left(\frac{d t}{2}\right)\left(\alpha_{h}-h\left(\alpha_{h}+\beta_{h}\right)\right)$

For the total current generated by the voltage-gated sodium current $\left(I_{V G S C}\right)$

$I_{\mathrm{VGSC}}=\bar{g}_{\mathrm{Na}} m^{2} h\left(E_{\mathrm{rev}}-V\right)$

where $V$ is the membrane potential, $m$ and $h$ are the activation and inactivation variables, $E_{\mathrm{rev}}$ is the reversal potential (set at $+55 \mathrm{mV}$ ) and $\bar{g}_{\mathrm{Na}}$ is the peak sodium conductance (set at $350 \mathrm{nS}$ ).

For the leak conductance, the constant field or GHK model provides us with a quantitative description of a non-linear IV relation of the type produced by a $\mathrm{K}_{2 \mathrm{P}}$ channel population where $z$ is the valence of charge; $F$, Faraday's constant (coulombs per mole); $T$, temperature (degrees Kelvin); $R$, gas constant (joules per mole-Kelvin); $\left[k_{\text {in }}\right]$ and $\left[k_{\text {out }}\right]$, concentration of potassium ions inside and outside the cell; and $\bar{g}_{\text {GHKleak }}$ is the slope conductance at $V \rightarrow \infty$ [9].

$I_{\text {GHKleak }}=V \frac{\bar{g}_{\text {GHKleak }}}{\left[k_{\text {in }}\right]}\left[\frac{\left\{\left[k_{\text {in }}\right]-\left[k_{\text {out }}\right] e^{\left(\frac{-V F}{R T}\right)}\right\}}{\left\{1-e^{\left(\frac{-V F}{R T}\right)}\right\}}\right]$

The linear leak conductance was based upon a simple ohmic resistance of the form:

$I_{\Omega \text { leak }}=\bar{g}_{\Omega \text { leak }}\left(E_{\text {rev }}-V\right)$

where $V$ is the membrane potential, $E_{\mathrm{rev}}$ is the reversal potential and $\bar{g}_{\Omega \text { leak }}$ is the value of the conductance. An $E_{\text {rev }}$ of $-98 \mathrm{mV}$ was chosen to match the reversal potential of the GHK leak.

Synaptic conductance waveforms were based upon the exponential difference synapse model of the form:

$I_{\text {EPSC }}(t)=\bar{g}_{\text {EPSC }} f\left\{\exp \left({ }^{\left(-t / \tau_{\text {decay }}\right)}-\exp ^{\left(-t / \tau_{\text {rise }}\right)}\right\}\right.$

where $t$ is the start of the synaptic waveform, $\bar{g}_{\text {EPSC }}$ is the peak synaptic conductance (varied between 0.5 and $10 \mathrm{nS}$ ), $f$ is a normalisation factor to ensure that the peak conductance equals $\bar{g}_{\text {EPSC }}$ and the rising phase is set by the smaller of the two time constants $\tau_{\text {rise }}$.
Reliable performance of the dynamic-clamp system requires minimal variation, or jitter, from cycle to cycle so that the requested arithmetical operations are achieved during each real-time loop. Operationally, the maximum jitter reported by the system when implementing this simple GHK-type leak was $2 \pm 0.05 \mu \mathrm{s}$, slowing down to $11 \pm 0.08 \mu \mathrm{s}$ with the voltage-gated sodium conductance. The properties of $I_{\mathrm{VGSC}}$ were chosen to ensure that all calculations were performed well within the sample interval of $50 \mu \mathrm{s}$.

Statistical analysis

All statistical tests were performed using STATISTICA 5.1 (StatSoft, Tulsa, OK) and considered significant at $P<0.05$. A Shapiro-Wilk test was used to determine whether measures were normally distributed, and differences between groups were examined using the Student's $t$ test or the MannWhitney $U$ test when distributions were not normal.

\section{Results}

Elimination of endogenous $\mathrm{K}_{\mathrm{V}}$ channels from the expression system

Before undertaking the dynamic-clamp experiments, we needed to ensure that endogenous $\mathrm{K}_{\mathrm{V}}$ channels did not contribute to AP repolarisation. Consistent with the presence of an endogenous $\mathrm{K}_{\mathrm{V}}$ channel population [47], there was a clear increase in membrane conductance (Fig. 2a) at command voltages more depolarised than $-20 \mathrm{mV}$, resulting in a steady-state outward conductance of $0.20 \pm 0.02 \mathrm{nS} /$ $\mathrm{pF}(n=5)$. The $K_{\mathrm{V}}$ blocker TEA significantly reduced the amplitude of this voltage-activated conductance with an $\mathrm{IC}_{50}$ of $0.7 \mathrm{mM}$ (Fig. 2c). No transient A-type conductance [28] was apparent in any recorded cell (Fig. 2a) with or without a prepulse to $-110 \mathrm{mV}$.

\section{TEA sensitivity of TASK-3 and TREK-1 channels}

Figure $2 \mathrm{~b}$ shows the IV curves generated from a GFP-positive cell in the presence and absence of $10 \mathrm{mM}$ TEA, demonstrating the modest TEA sensitivity of $\mathrm{K}_{2 \mathrm{P}}$ channels. In these voltage-clamp experiments, the $\mathrm{K}_{2 \mathrm{P}}$-mediated conductance is recorded during a ramp protocol from -20 to $-150 \mathrm{mV}$ to avoid any contamination from the endogenous $\mathrm{K}_{\mathrm{V}}$ conductance. TEA produced a consistent block of both the TASK-3and TREK-1-mediated potassium leak conductance $\left(G_{\mathrm{K}}\right)$. As shown in Fig. 2c, we observed a fully reversible $15.8 \pm 2.5 \%$ block of TASK-3 $(n=9)$, and a $25.2 \pm 0.6 \%$ block of the TREK-1 $(n=4)$ mediated conductance at a TEA concentration of $10 \mathrm{mM}$. As shown in Fig. $2 \mathrm{c}$, the $\mathrm{IC}_{50}$ for the $\mathrm{K}_{2 \mathrm{P}}$-mediated conductance was extrapolated to be in the region of $300 \mathrm{mM}$. 
Therefore, all subsequent experiments were performed in the presence of $10 \mathrm{mM}$ TEA, providing a system in which the biophysical and pharmacological properties of recombinant proteins could be studied in the absence of $K_{\mathrm{V}}$ currents.

Influence of TASK-3 and TREK-1 channel expression on $\mathrm{G}_{\mathrm{K}}$ and $\mathrm{RMP}$

Figure $2 \mathrm{~b}$ also compares the IV curves generated from GFPpositive and GFP-negative (un-transfected) cells, demonstrating the characteristic non-linear conductance that results from open rectification of $\mathrm{K}_{2 \mathrm{P}}$ channels. The non-linear leak conductance generated in TASK-3/GFP-expressing cells increases from $0.63 \pm 0.01 \mathrm{nS} / \mathrm{pF}$ at $-60 \mathrm{mV}(n=101)$ to $1.05 \pm$ $0.01 \mathrm{nS} / \mathrm{pF}$ at $-20 \mathrm{mV}(n=101)$. On average, TREK-1/GFP expression resulted in a smaller non-linear leak conductance that increases from $0.14 \pm 0.01 \mathrm{nS} / \mathrm{pF}(n=30)$ at $-60 \mathrm{mV}$ to $0.31 \pm 0.01 \mathrm{nS} / \mathrm{pF}(n=30)$ at $-20 \mathrm{mV}$. In contrast, GFPnegative cells exhibited a small inward leak that was linear over the -60 to $-20 \mathrm{mV}$ range, with an average conductance of only $-0.01 \pm 0.0002 \mathrm{nS} / \mathrm{pF}(n=82)$. The difference in potassium leak generated by TREK-1 and TASK-3 channel expression most likely reflects differences in channel density. These differences should influence the cells RMP. Indeed, TREK-1 transfected cells had average RMPs of $-64.9 \pm$ $0.7 \mathrm{mV}(n=31)$ compared with $-73.0 \pm 0.1 \mathrm{mV}(n=103)$, in TASK-3-expressing cells. Nevertheless, both of these RMPs were significantly more hyperpolarised than un-transfected cells ( $-24.6 \pm 0.2 \mathrm{mV} ; n=36)$. As shown in Fig. 2 d, plotting the relationship between $G_{\mathrm{K}}$ and RMP for all GFP-negative, TASK-3/GFP- and TREK-1/GFP-expressing cells $(n=212)$ results in a distribution that is well described by a first-order exponential function reaching asymptote $(-79.3 \mathrm{mV})$ at around $0.5 \mathrm{nS} / \mathrm{pF}$.

\section{The minimum requirements for AP propagation}

In order to mimic the presence of $\mathrm{Na}_{\mathrm{V}}$ channels in these cells, transient conductance changes of the type shown in Fig. 1 were mimicked by a simple set of Hodgkin-Huxley equations (see "Methods"). AP generation was not possible in GFPnegative cells. However, implementing a virtual sodium conductance in TREK-1-expressing cells resulted in robust APs with fast rise and decay and none after hyperpolarisation. This was true of all TREK-1- and TASK-3-expressing cells examined $(n=20)$. Although a $\mathrm{K}_{2 \mathrm{P}}$-mediated potassium leak conductance was clearly sufficient to repolarise the membrane, it was also clear that the AP width and height was variable from cell to cell. This variability in AP shape correlated with the magnitude of $G_{\mathrm{K}}$, as did the RMP and the current required to achieve AP threshold. Comparing the three examples shown in Fig. 3, it is clear that a larger $G_{\mathrm{K}}$ results in a faster membrane time constant and a correspondingly briefer AP. The faster membrane time constant is apparent in the subthreshold membrane response shown for each example. These data demonstrate how $\mathrm{K}_{2 \mathrm{P}}$ channel expression will be sufficient to repolarise the membrane following the activation/ inactivation of $\mathrm{Na}_{\mathrm{V}}$ channels leading to rapid $\mathrm{Na}_{\mathrm{V}}$ deactivation in the absence of functional $K_{\mathrm{V}}$ channels. Also note that AP generated in the absence of $\mathrm{Kv}$ channels lack membrane after hyperpolarisation which is seen when $K_{\mathrm{V}}$ channels are also present. Membrane after hyperpolarisation facilitates the recovery of $\mathrm{Na}_{\mathrm{V}}$ channels from inactivation and therefore aids high frequency firing.

\section{Ability of $K_{2 P}$ channels to support sustained AP firing}

Next, we examined whether the presence of $\mathrm{K}_{2 \mathrm{P}}$ channels enables sustained AP firing in response to a tonic depolarising stimulus. At low levels of $\mathrm{K}_{2 \mathrm{P}}$ channel expression, the ability to generate a single AP in response to a brief current pulse did not translate into continuous AP firing during sustained depolarisation. The top panel in Fig. 3 illustrates a cell that was not able to support continuous AP firing during longer current pulses, although the potassium leak conductance was able to repolarise the membrane during a single AP. In this cell, activation of the virtual sodium conductance at around $-40 \mathrm{mV}$ results in the initial AP upstroke, but the membrane was then maintained at around $-20 \mathrm{mV}$ throughout the depolarising current pulse (data not shown). High-frequency AP firing was apparent during sustained depolarisation only in those cells that exhibited larger $G_{\mathrm{K}}$ values. For example, the middle trace in Fig. 3 is taken from a cell with a $G_{\mathrm{K}}$ of $0.8 \mathrm{nS} /$ $\mathrm{pF}$, and this cell did support high-frequency sustained firing during longer depolarising current pulses. Differences in $G_{\mathrm{K}}$ also explained why in TASK-3-expressing cells the current required to reach AP threshold $\left(I_{\mathrm{AP}}\right)$ for a $300-\mathrm{ms}$ current pulse was $45.4 \pm 12.4 \mathrm{pA} / \mathrm{pF}(n=11)$ compared with $25.6 \pm$ $10.3 \mathrm{pA} / \mathrm{pF}(n=6)$ in TREK-1-expressing cells. Figure $4 \mathrm{~d}$ also shows that, between cells, the variability in $I_{\mathrm{AP}}$ was clearly correlated with differences in $G_{\mathrm{K}}$, but, once AP threshold was reached, the slope of the change in AP firing rate together with the maximum AP frequency did not correlate with $G_{\mathrm{K}}$.

Overall, as well as demonstrating the ability of the $\mathrm{K}_{2 \mathrm{P}^{-}}$ mediated conductance to support AP firing, these conductance simulation experiments demonstrate how a larger $G_{\mathrm{K}}$ results in a faster membrane time constant and therefore a briefer AP. The influence of $G_{\mathrm{K}}$ on the AP rise, peak and decay for all cells examined during the conductance simulation protocol is shown in Fig. 5. There is no obvious relationship between the magnitude of $G_{\mathrm{K}}$ and the AP peak amplitude, but the rate of AP rise clearly increases from 0 to $0.5 \mathrm{nS} / \mathrm{pF}(n=15)$. The slower rate of AP decay is less obviously affected by alterations in $G_{\mathrm{K}}$. During these particular conductance simulation experiments, only five cells generated $\mathrm{K}_{2 \mathrm{P}}$ leaks exceeding $0.5 \mathrm{nS} / \mathrm{pF}$, and we did not often encounter cells with $\mathrm{G}_{\mathrm{K}}$ 
greater than $2 \mathrm{nS} / \mathrm{pF}$. Therefore, it is difficult to comment on the relationship between $G_{\mathrm{K}}$ and AP properties at higher levels of $\mathrm{K}_{2 \mathrm{P}}$ expression, but the rate of AP rise peaks in the region of $0.5 \mathrm{nS} / \mathrm{pF}$. It is also clear from these data that, over the range of $G_{\mathrm{K}}$ examined, AP peak and decay were not altered.

\section{Effect of a volatile anaesthetic on cell excitability}

The relationship between $G_{\mathrm{K}}$ and AP properties was also examined by taking advantage of the enhancement of $\mathrm{K}_{2 \mathrm{P}}$ channel activity with the volatile anaesthetic halothane [37]. As shown in Fig. 6a, voltage-clamp experiments confirmed that bath application of $2 \%$ halothane resulted in a significant $74 \pm 36 \%(n=5)$ increase in the magnitude of $G_{\mathrm{K}}$. Although the halothane-induced increase in $G_{\mathrm{K}}$ was modest at this relatively low concentration, it was consistent, increasing from an average value of $0.6 \pm 0.3$ to $0.7 \pm 0.1 \mathrm{nS} / \mathrm{pF}$. In a separate series of conductance simulation experiments $(n=$ 7 ), the result of this increased $G_{\mathrm{K}}$ was assessed on AP prop-

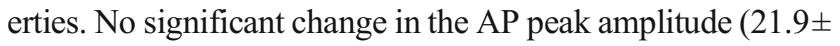
$2.7 \mathrm{mV}$ versus $22.6 \pm 3.1 \mathrm{mV}$ ) was observed, but, as shown in Fig. 6 b, the rate of AP rise and decay were both significantly increased. The average rate of AP rise was increased by $13.2 \pm$ $7.0 \%(n=7)$, from an average value of $83.8 \pm 14.0$ to $93.6 \pm$ $15.0 \mathrm{mV} / \mathrm{ms}$ in the presence of $2 \%$ halothane. The rate of AP decay was increased by a similar degree $(16.0 \pm 7.9 \%)$, from an average value $-28.6 \pm 4.3$ to $-31.6 \pm 3.6 \mathrm{mV} / \mathrm{ms}$. It is interesting to note that there was no significant change in the RMP during halothane application, reflecting the relationship between $G_{\mathrm{K}}$ and RMP that has been illustrated in Fig. 2d. It can be seen from this relationship that, in situations where the cells RMP is dominated by the membranes potassium permeability, asymptote is reached at $G_{\mathrm{K}}$ values close to $0.5 \mathrm{nS} / \mathrm{pF}$, and any further increase in $G_{\mathrm{K}}$ will not impact on the RMP. However, one other functional consequence of increasing $G_{\mathrm{K}}$ with halothane was reflected in the current required to reach AP threshold that increased in all cells examined from an average value of $31.7 \pm 9.4$ to $36.9 \pm 9.4 \mathrm{pA} / \mathrm{pF}(n=6)$.

\section{Discussion}

Recombinant expression procedures were used to examine the biophysical impact of $\mathrm{K}_{2 \mathrm{P}}$ channel expression on AP

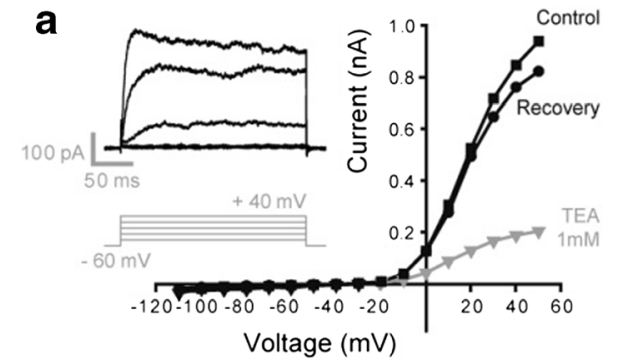

C

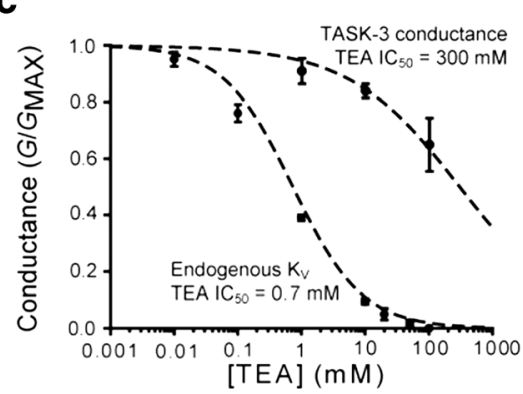

Fig. 2 Removal of the endogenous voltage-gated potassium channels from the expression system. a Characterisation of conductances in HEK293 cells illustrating the activation of an endogenous $K_{\mathrm{V}}$ near $0 \mathrm{mV}$. The insert shows a series of current records elicited by voltage steps from -100 to $+40 \mathrm{mV}$. The current-voltage relationship of this $K_{\mathrm{V}}$ current has been plotted for recordings made in the presence (grey triangles) and absence (black symbols) of $1 \mathrm{mM}$ TEA. b A voltage ramp from -20 to $-150 \mathrm{mV}$ was used to study the non-linear leak conductance present following TASK-3 and TREK-1 transfection. The current-voltage relationship of the resulting potassium leak conductance $\left(G_{\mathrm{K}}\right)$ recorded from a TREK-1-transfected cell is shown in the presence (grey trace) and absence (black trace) of $10 \mathrm{mM}$ TEA. For comparison, the currentvoltage relationship for another un-transfected cell is also plotted to illustrate the small endogenous linear leak that is also present in these
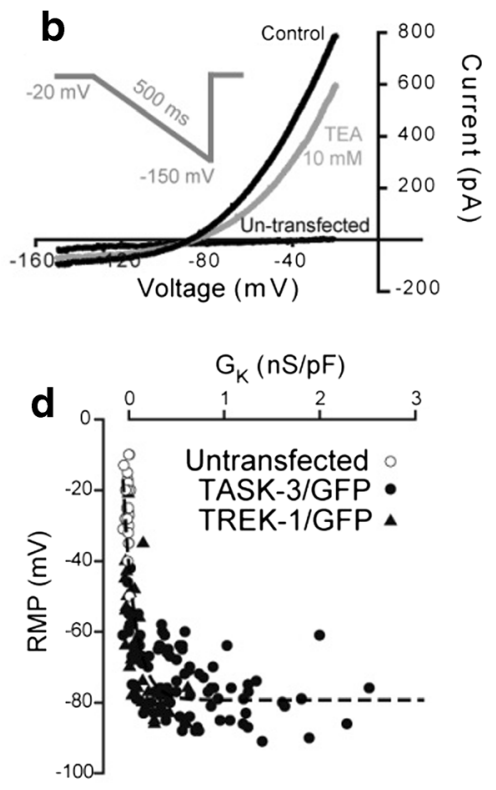

cells. Note the lack of any endogenous $K_{\mathrm{V}}$ activation over the voltage ranges examined in the absence of TEA. c Inhibition curves were constructed from data obtained following TEA block of the endogenous $\mathrm{K}_{\mathrm{V}}$ and the TASK-3-mediated $\mathrm{K}_{2 \mathrm{P}}$ conductance. The data were welldescribed with a modified Hill equation (dashed lines) to give an estimate of the $\mathrm{IC}_{50}$ for this drug-receptor interaction. From these fits, it is clear that the endogenous $K_{\mathrm{V}}$ is sensitive to TEA with an $\mathrm{IC}_{50}$ of $0.7 \mathrm{mM}$, whereas the TASK-3 conductance is relatively insensitive to this blocker with an extrapolated $\mathrm{IC}_{50}$ of $300 \mathrm{mM}$. d In order to examine the relationship between $G_{\mathrm{K}}$ and the RMP, results were pooled from all cells transfected with either TASK-3 (filled circles) or TREK-1 (filled triangles), and for un-transfected cells (open circles). The data set was well described by a single exponential function (dashed line) 

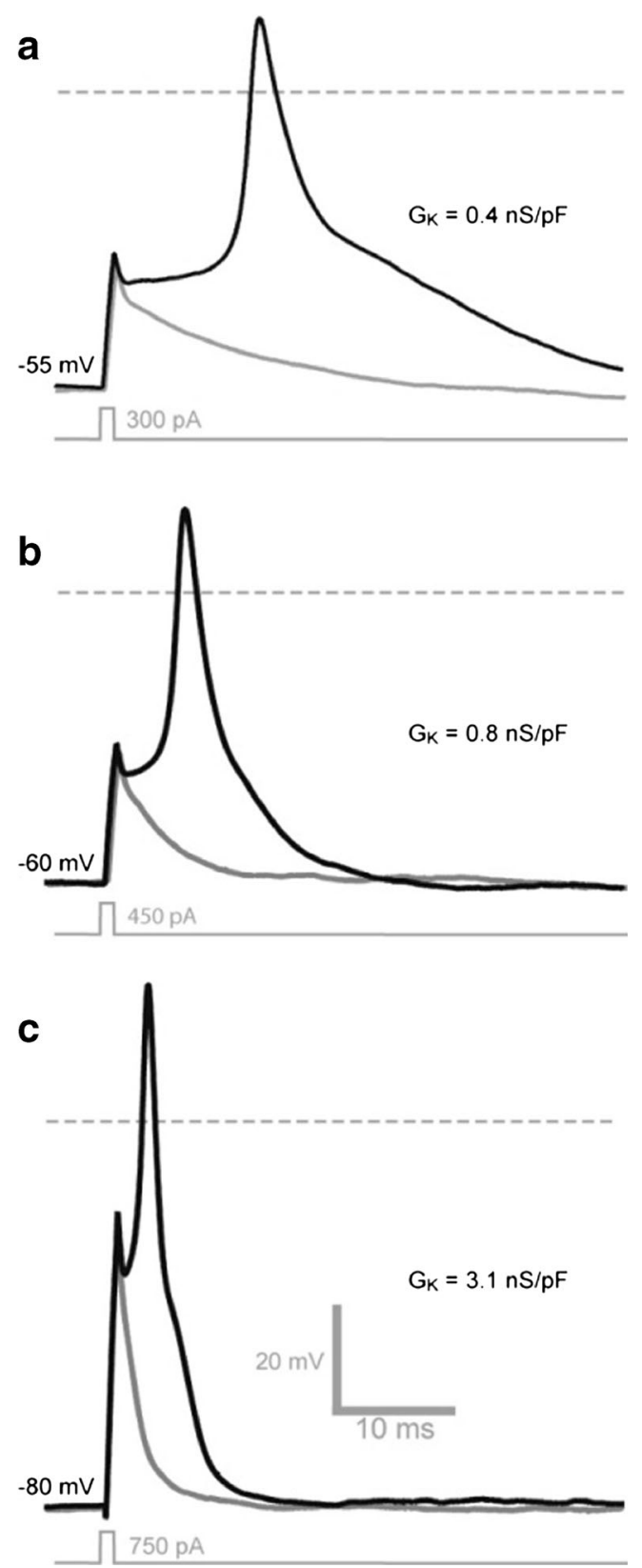

Fig. 3 Two-pore domain potassium channel expression is sufficient to repolarise the AP. a, $\mathbf{b}$ and $\mathbf{c}$ Single AP generated in response to a brief 1$\mathrm{ms}$ current injection in three individual cells expressing TREK-1 channels. The grey dashed line illustrates the $0 \mathrm{mV}$ level. The magnitude of $G_{\mathrm{K}}$ was smallest in $\mathbf{a}(0.4 \mathrm{nS} / \mathrm{pF})$ and largest in $\mathbf{c}(3.1 \mathrm{nS} /$ $\mathrm{pF})$. The magnitude of $G_{\mathrm{K}}$ correlates with the RMP of the HEK cell, the current required to reach AP threshold, and the duration of the AP. The sub-threshold voltage response is also shown for each cell (grey line) to further demonstrate the faster membrane time constant that is apparent at larger values of $G_{\mathrm{K}}$

generation by implementing a virtual voltage-gated sodium conductance in the HEK cells. This application of the conductance simulation approach clearly demonstrates that $K_{\mathrm{V}}$ channels are not an absolute requirement for AP generation, and the voltage-independent potassium leak conductance generated by $\mathrm{K}_{2 \mathrm{P}}$ channels is sufficient to repolarise the AP. In
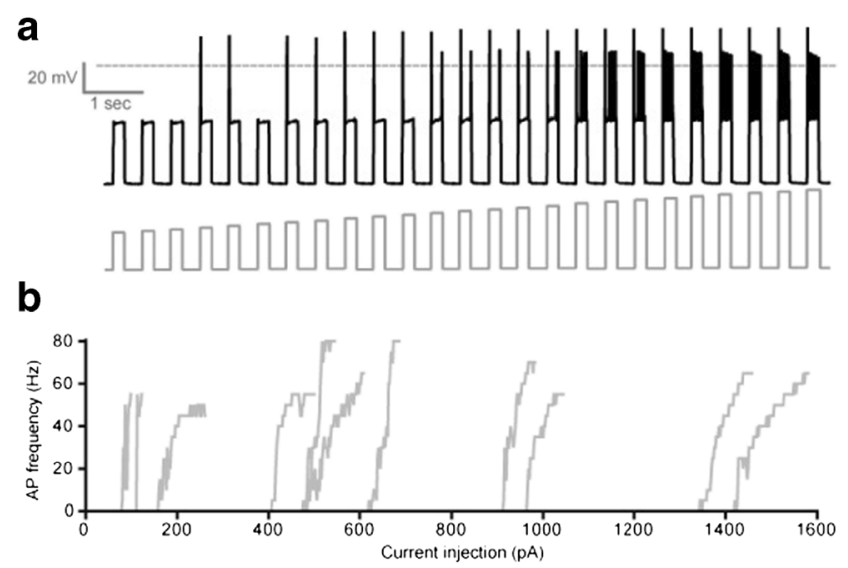

C

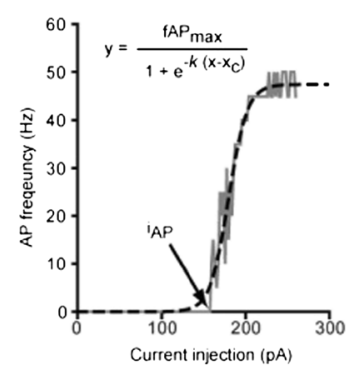

d

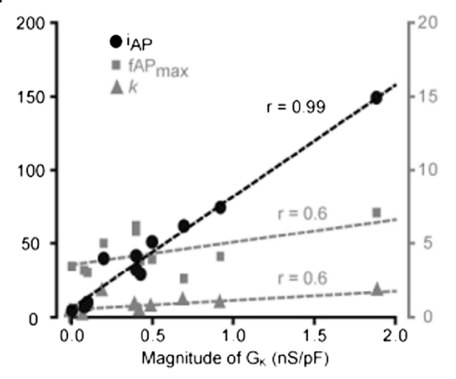

Fig. $4 \mathrm{~K}_{2 \mathrm{P}}$ channel expression alters the current required to reach $\mathrm{AP}$ threshold. a Continuous voltage recording (black trace) obtained during a conductance simulation experiment from a HEK cell expressing TASK-3 channels. A series of long-duration 300-ms depolarising current pulses (grey trace) were applied at increasing current intensities. The relationship between the magnitude of the injected current and the AP frequency for all cells examined in this way is plotted in panel $\mathbf{b}$. Analysis of a single cells AP frequency response to injected current is shown in panel c. This relationship is well described by a simple Boltzmann-type function (dashed line). From this analysis, we can estimate the current required to reach $\mathrm{AP}$ threshold $\left(i_{\mathrm{AP}}\right)$, the slope of the relationship $(k)$ and the maximum AP frequency ( $\left(\mathrm{AP}_{\max }\right)$. d The results of fitting linear regressions to the relationship between $G_{\mathrm{K}}$ and the three variables $\left(i_{\mathrm{AP}}\right.$, $k$, and $\mathrm{fAP}_{\max }$ ) extracted from the data shown in $\mathbf{b}$. It is clear that the only correlation is between the current required to reach $\mathrm{AP}$ threshold $\left(i_{\mathrm{AP}}\right)$ and the magnitude of the potassium leak $\left(G_{\mathrm{K}}\right)$

light of this observation, we discuss the role of axonal $\mathrm{K}_{2 \mathrm{P}}$ channels in AP generation and consider the impact of $\mathrm{K}_{2 \mathrm{P}}$ channel modulation during anaesthesia.

The endogenous $K_{\mathrm{V}}$ conductance present in these cells is small compared with the recombinant $\mathrm{K}_{2 \mathrm{P}}$ conductance, but it was still necessary to pharmacologically remove this confounding influence during the conductance simulation experiments. Performing experiments in the presence of $10 \mathrm{mM}$ TEA reduced the magnitude of the recombinant $\mathrm{K}_{2 \mathrm{P}}$-mediated conductance, but the remaining non-linear leak conductance was clearly sufficient to enable AP generation in a manner predicted from our simulation studies. The magnitude of the $G_{\mathrm{K}}$ produced by our expression system was never sufficient to generate a resistive shunt capable of complete AP attenuation. This could well reflect an upper limit for the expression of $\mathrm{K}_{2 \mathrm{P}}$ channels in biological membranes. Nevertheless, when 

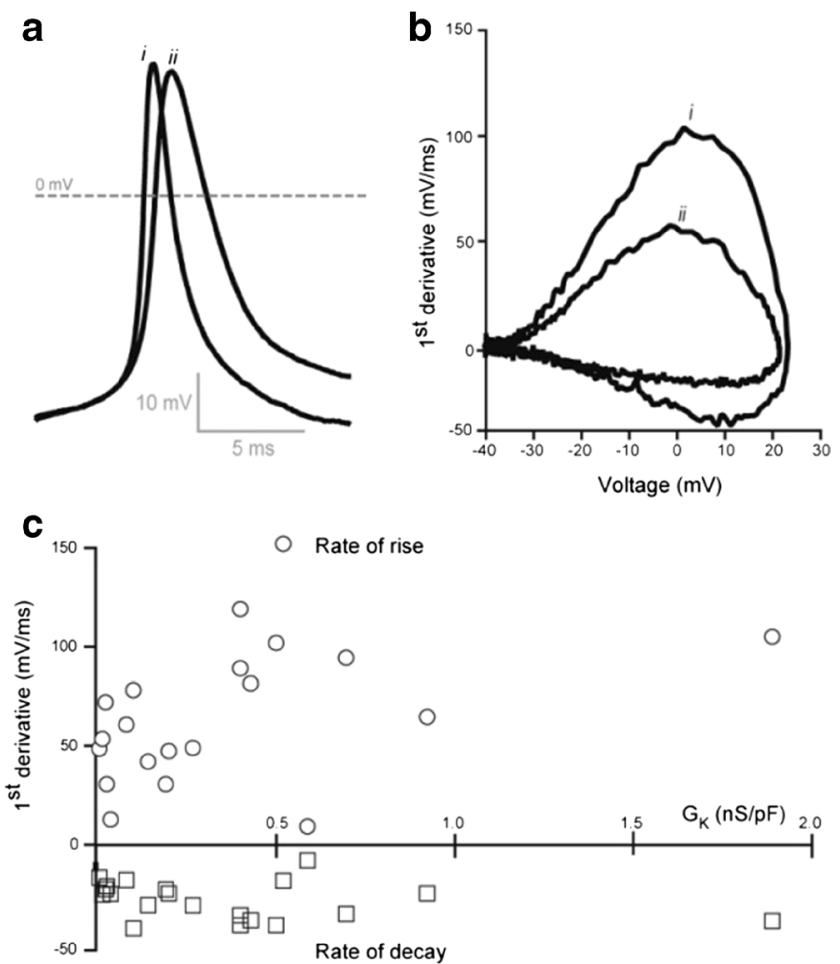

Fig. 5 Relationship between the magnitude of the $K_{2 P}$-mediated conductance and the AP rise and decay. a Two threshold APs from separate cells are superimposed to illustrate the difference in AP rise and decay. The first AP (i) comes from a cell with a $G_{\mathrm{K}}$ of $0.1 \mathrm{nS} / \mathrm{pF}$ whereas the second AP (ii) comes from a cell with a $G_{\mathrm{K}}$ of $0.5 \mathrm{nS} / \mathrm{pF}$. b Phase plane plots of the two APs shown in a. The maximum AP rise and decay was calculated from these plots. $\mathbf{c}$ Plot of the maximum AP rise (open circles) and decay (open squares) for all threshold APs elicited during conductance simulation procedure in relation to the $G_{\mathrm{K}}$ for each cell examined

considering the entire dataset, it is clear that a larger $G_{\mathrm{K}}$ results in briefer APs due to the generation of a faster membrane time constant. It is worth noting that the magnitude of $G_{\mathrm{K}}$ observed in this expression system correlates well with the values obtained in native neurones. For example, in adult CGNs, the standing outward potassium conductance is $0.5 \mathrm{nS} / \mathrm{pF}$ in wild-type mice and is reduced to $0.3 \mathrm{nS} / \mathrm{pF}$ in the TASK-3 KO mice [9]. In addition to broadening the AP, this reduction in the TASK-mediated conductance depolarises the RMP and ultimately leads to a failure to sustain AP firing during continuous excitatory drive as AP accommodation becomes more likely as the underlying $\mathrm{Na}_{\mathrm{V}}$ channels experience significant steady-state inactivation at depolarised potentials. Obviously, the impact of $\mathrm{K}_{2 \mathrm{P}}$ channels on these various aspects of neuronal excitability may not be so pronounced in all cell types as the relative contribution of this potassium leak conductance will vary for different cell-types. Nevertheless, it is worth considering that any neuromodulation that results in a reduced $\mathrm{K}_{2 \mathrm{p}}$-mediated conductance, for example, activation of Gprotein coupled receptors, will influence more than just membrane hyperpolarisation.

\section{a}

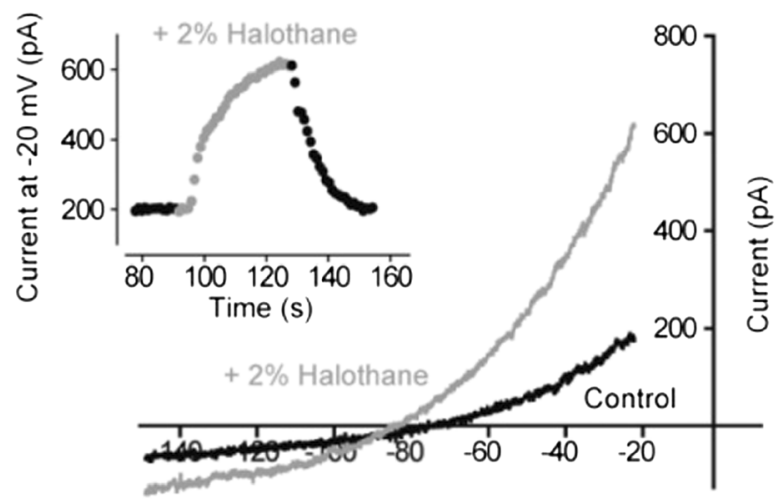

b
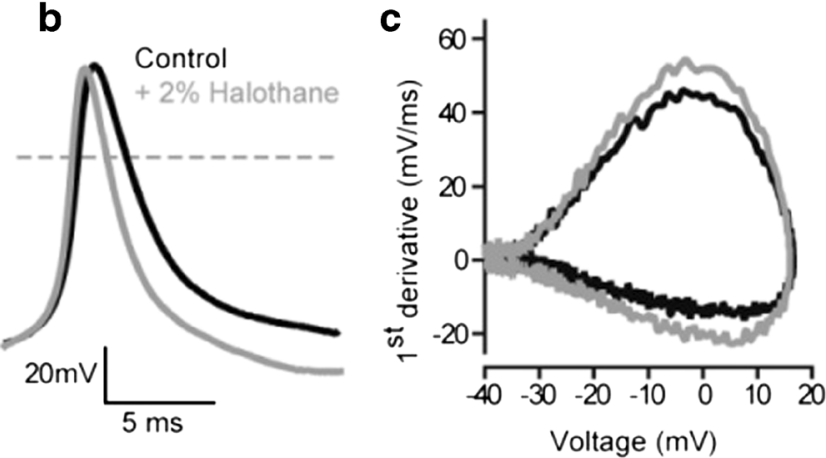

Fig. 6 Actions of halothane on $\mathrm{K}_{2 \mathrm{P}}$ channels and the consequence of this enhancement for AP properties. a Results from a voltage-clamp experiment illustrating the current-voltage relationship for a TASK-3-expressing cell during a standard ramp protocol in the presence (grey trace) and absence (black trace) of $2 \%$ halothane. The insert shows the time course of the halothane enhancement for this cell calculated at a command potential of $-20 \mathrm{mV}$. b A single threshold AP elicited from a different TASK-3expressing cell in the presence (grey trace) and absence (black trace) of $2 \%$ halothane. The dashed line illustrates the $0 \mathrm{mV}$ level. c Phase plane plots for the APs shown in $\mathbf{b}$ illustrating the modest speeding of the AP rise and decay in the presence (grey trace) of $2 \%$ halothane

Physiological implications of $\mathrm{K}_{2 \mathrm{P}}$ channel expression in axons

Recordings from mammalian myelinated axons are characterised by a conspicuous absence of $K_{\mathrm{V}}$ currents [11, 13, 27, 31]. It is now apparent that $K_{\mathrm{V}} 1$-type channels are restricted to the juxtaparanodal region of mammalian axons $[3,39-42,48,49]$ and are effectively hidden under the myelin. The functional significance of juxtaparanodal $K_{\mathrm{V}}$ channels in mammalian axons is therefore unclear as they do not directly contribute to AP propagation [50]. To account for a lack of functional $K_{\mathrm{V}}$ channels, AP propagation in mammalian myelinated axons has been explained in terms of rapid sodium channel activation/inactivation in combination with a sizable leak conductance $[24,30]$. Indeed, both the Chiu-Ritchie-StaffStagg model [13] and the Schwarz-Eikhof model [44] rely on a leak conductance to repolarise the AP in the absence of a $K_{\mathrm{V}}$-like conductance. Although a potassium leak conductance is evident in recordings from myelinated axons [32], the origin 
of the nodal leak conductance is still not certain, and its contribution to AP generation has not been critically evaluated. Indeed, it has been suggested that the voltage-independent leak may not reflect the presence of a nodal potassium channel but could involve an extracellular pathway beneath the myelin that connects the nodal and internodal regions [5, 7]. However, this hypothesis is partly based upon the unusual biophysical and pharmacological properties of this leak conductance, namely its voltage-independence and TEA insensitivity. Voltageindependence and TEA insensitivity are now known to be defining features of $\mathrm{K}_{2 \mathrm{P}}$ channels [17, 22, 30, 36]. It has recently been shown that KCNQ2/3 channels are localized to mammalian nodes where they contribute to the maintenance of the RMP $[3,15,45]$. However, due to their slow, voltagedependent activation kinetics and TEA sensitivity [29], it is unlikely that they are the sole contributor to the potassium leak conductance or to the repolarisating phase of APs at the node. Indeed, blockade of KCNQ currents reveals a substantial leak component and does not prevent the repolarisation of the membrane following an AP $[15,45]$. The suggestion that, in combination with $\mathrm{Na}_{\mathrm{V}}$ channels, $\mathrm{K}_{2 \mathrm{P}}$ channels could provide the potassium leak necessary to generate APs in the absence of $\mathrm{K}_{\mathrm{V}} 1$ channels is therefore intriguing $[9,30]$, but future studies are needed to directly examine the contributions made by $\mathrm{K}_{2 \mathrm{P}}$ channels to the potassium permeability of mammalian myelinated axons.

\section{Clinical implications of $\mathrm{K}_{2 \mathrm{P}}$ channel modulators}

Anaesthetic mechanisms are often considered to involve interactions with a diverse array of receptor types, but it is also possible that the actions of specific anaesthetics could be explained by an interaction with a limited number of sites [18, 20]. Volatile anaesthetics, like halothane, are known to potently enhance the open probability of both TASK-3 and TREK-1 channels [19]. However, it is not clear what the consequence of this modulation would be for neuronal excitability as halothane is also known to modulate $\mathrm{Na}_{\mathrm{V}}$ kinetics and enhance inhibition due to enhancement of $\mathrm{GABA}_{\mathrm{A}}$ receptor openings. The use of the conductance simulation technique in combination with a recombinant expression system has allowed us to examine the consequence of halothane's modulation of neuronal excitability in a system where the only possible site of drug action is the $\mathrm{K}_{2 \mathrm{P}}$ channel. As expected, the halothane-induced enhancement of $G_{\mathrm{K}}$ increased the current required to reach AP threshold with little change in the actual RMP. Therefore, in a neuronal population where the predominant leak conductance arises from a $\mathrm{K}_{2 \mathrm{P}}$ channel population, dampening of neuronal excitability by halothane will predominantly arise from a resistive shunt of any synaptic conductance. Another consequence of increased $G_{\mathrm{K}}$ in a system like this is the faster membrane time constant that inevitably leads to a briefer AP. The functional significance of any halothane-induced alteration in AP duration is less clear.
AP duration is known to influence the transmitter profile in the synaptic cleft by altering the profile of calcium influx into the nerve terminal $[4,46]$. A study using a synaptosome preparation has indicated that the amount of glutamate and GABA released from cerebrocortical nerve terminals is influenced by the presence of TREK-1 channels [51], but it remains to be seen what contribution, if any, $\mathrm{K}_{2 \mathrm{P}}$ channels make to the excitability of the intact axon.

If $\mathrm{K}_{2 \mathrm{P}}$ channels were found to contribute to the excitability of the axonal membrane, this could also have important implications for the action of local anaesthetics [30]. A voltageindependent so-called flicker potassium channel has been reported in myelinated axons [32]. This channel population is relatively TEA-insensitive and also blocked by the local anaesthetic bupivacaine $[8,32]$, leading to the suggestion that $\mathrm{K}_{2 \mathrm{P}}$ channel expression could underlie the potassium permeability of the axonal membrane [35]. Furthermore, the blocking action of bupivicaine is $\mathrm{pH}$-sensitive, suggesting that members of the TASK channel family could underlie this potassium leak conductance. The reduced $G_{\mathrm{K}}$ resulting from $\mathrm{K}_{2 \mathrm{P}}$ channel block could lead to inactivation of $\mathrm{Na}_{\mathrm{V}}$ channels due to increased depolarisation block, and this may represent a novel mode of action for local anaesthetics [30]. $\mathrm{K}_{2 \mathrm{P}}$ channels are expressed in dorsal root ganglion and trigeminal ganglia neurons, and data from $\mathrm{KO}[2]$ and genetic studies [16, 34] highlight the importance of $\mathrm{K}_{2 \mathrm{P}}$ channels in pain perception and sensitization (for a review, see [38]). However, the exact subcellular localisation of $\mathrm{K}_{2 \mathrm{P}}$ channels in nociceptors has yet to be determined. Therefore, before the involvement of $\mathrm{K}_{2 \mathrm{P}}$ channels in the mechanism of anaesthetic action can be explored further, more information is required on the anatomical location and functional significance of $\mathrm{K}_{2 \mathrm{P}}$ expression in mammalian axons.

Acknowledgements Prof. William Wisden made valuable comments on this manuscript. We would like to thank Timothy Murray, Dinesh Sivakumar and Raquel Yustos for their technical contributions to this project. This work has been funded by the Wellcome Trust, the Medical Research Council and The Royal Society. G.M received a Biotechnology and Biological Sciences Research Council PhD studentship.

Open Access This article is distributed under the terms of the Creative Commons Attribution License which permits any use, distribution, and reproduction in any medium, provided the original author(s) and the source are credited.

\section{References}

1. Aller MI, Veale EL, Linden AM, Sandu C, Schwaninger M, Evans LJ, Korpi ER, Mathie A, Wisden W, Brickley SG (2005) Modifying the subunit composition of TASK channels alters the modulation of a leak conductance in cerebellar granule neurons. J Neurosci 25(49):11455-67

2. Alloui A, Zimmermann K, Mamet J, Duprat F, Noel J, Chemin J, Guy N, Blondeau N, Voilley N, Rubat-Coudert C, Borsotto M, 
Romey G, Heurteaux C, Reeh P, Eschalier A, Lazdunski M (2006) TREK-1, a $\mathrm{K}+$ channel involved in polymodal pain perception. EMBO J 25(11):2368-76. doi:10.1038/sj.emboj.7601116

3. Arancibia-Carcamo IL, Attwell D (2014) The node of Ranvier in CNS pathology. Acta Neuropathol 128(2):161-75. doi:10.1007/ s00401-014-1305-Z

4. Augustine GJ (1990) Regulation of transmitter release at the squid giant synapse by presynaptic delayed rectifier potassium current. J Physiol 431:343-64

5. Barrett EF, Barrett JN (1982) Intracellular recording from vertebrate myelinated axons: mechanism of the depolarizing afterpotential. J Physiol 323:117-44

6. Bean BP (2007) The action potential in mammalian central neurons. Nat Rev Neurosci 8(6):451-65

7. Blight AR (1985) Computer simulation of action potentials and afterpotentials in mammalian myelinated axons: the case for a lower resistance myelin sheath. Neuroscience 15(1):13-31

8. Brau ME, Nau C, Hempelmann G, Vogel W (1995) Local anesthetics potently block a potential insensitive potassium channel in myelinated nerve. J Gen Physiol 105(4):485-505

9. Brickley SG, Aller MI, Sandu C, Veale EL, Alder FG, Sambi H, Mathie A, Wisden W (2007) TASK-3 two-pore domain potassium channels enable sustained high-frequency firing in cerebellar granule neurons. J Neurosci 27(35):9329-40

10. Brickley SG, Revilla V, Cull-Candy SG, Wisden W, Farrant M (2001) Adaptive regulation of neuronal excitability by a voltageindependent potassium conductance. Nature 409(6816):88-92

11. Brismar T (1980) Potential clamp analysis of membrane currents in rat myelinated nerve fibres. J Physiol 298:171-84

12. Cathala L, Brickley S, Cull-Candy S, Farrant M (2003) Maturation of EPSCs and intrinsic membrane properties enhances precision at a cerebellar synapse. J Neurosci 23(14):6074-85

13. Chiu SY, Ritchie JM, Rogart RB, Stagg D (1979) A quantitative description of membrane currents in rabbit myelinated nerve. $\mathrm{J}$ Physiol 292:149-66

14. Cole KS (1949) Some physical aspects of bioelectric phenomena. Proc Natl Acad Sci U S A 35(10):558-66

15. Devaux JJ, Kleopa KA, Cooper EC, Scherer SS (2004) KCNQ2 is a nodal K+ channel. J Neurosci 24(5):1236-44. doi:10.1523/ JNEUROSCI.4512-03.2004

16. Enyedi P, Braun G, Czirjak G (2012) TRESK: the lone ranger of twopore domain potassium channels. Mol Cell Endocrinol 353(1-2):7581. doi:10.1016/j.mce.2011.11.009

17. Enyedi P, Czirjak G (2010) Molecular background of leak K+ currents: two-pore domain potassium channels. Physiol Rev 90(2):559605. doi:10.1152/physrev.00029.2009

18. Franks NP (2006) Molecular targets underlying general anaesthesia. Br J Pharmacol 147(Suppl 1):S72-81

19. Franks NP, Honore E (2004) The TREK K2P channels and their role in general anaesthesia and neuroprotection. Trends Pharmacol Sci 25(11):601-8

20. Franks NP, Lieb WR (1994) Molecular and cellular mechanisms of general anaesthesia. Nature 367(6464):607-14

21. Goldman D (1943) Potential, impedance, and rectification in membranes. J Gen Physiol 27:37-60

22. Goldstein SA, Bockenhauer D, O'Kelly I, Zilberberg N (2001) Potassium leak channels and the KCNK family of two-P-domain subunits. Nat Rev Neurosci 2(3):175-84

23. Gonzalez JA, Jensen LT, Doyle SE, Miranda-Anaya M, Menaker M, Fugger L, Bayliss DA, Burdakov D (2009) Deletion of TASK1 and TASK3 channels disrupts intrinsic excitability but does not abolish glucose or $\mathrm{pH}$ responses of orexin/hypocretin neurons. Eur J Neurosci 30(1):57-64. doi:10.1111/ j.1460-9568.2009.06789.x
24. Hille B (1973) Potassium channels in myelinated nerve. Selective permeability to small cations. J Gen Physiol 61(6): 669-86

25. Hodgkin AL, Huxley AF (1952) A quantitative description of membrane current and its application to conduction and excitation in nerve. J Physiol 117(4):500-44

26. Hodgkin AL, Katz B (1949) The effect of sodium ions on the electrical activity of the giant axon of the squid. J Physiol 108(1): $37-77$

27. Horackova M, Nonner W, Stampfli R (1968) Action potentials and voltage clamp currents of single rat Ranvier nodes. Proc intl Union Physiol Sci 7:198

28. Jiang B, Sun X, Cao K, Wang R (2002) Endogenous Kv channels in human embryonic kidney (HEK-293) cells. Mol Cell Biochem 238(1-2):69-79

29. Jow F, Wang K (2000) Cloning and functional expression of rKCNQ2 $\mathrm{K}(+)$ channel from rat brain. Brain Res Mol Brain Res 80(2):269-78

30. Kindler CH, Yost CS (2005) Two-pore domain potassium channels: new sites of local anesthetic action and toxicity. Reg Anesth Pain Med 30(3):260-74

31. Kocsis JD, Waxman SG (1980) Absence of potassium conductance in central myelinated axons. Nature 287(5780):348-9

32. Koh DS, Jonas P, Brau ME, Vogel W (1992) A TEA-insensitive flickering potassium channel active around the resting potential in myelinated nerve. J Membr Biol 130(2):149-62

33. Kullmann PH, Wheeler DW, Beacom J, Horn JP (2004) Implementation of a fast 16-bit dynamic clamp using LabVIEWRT. J Neurophysiol 91(1):542-54

34. Lafreniere RG, Cader MZ, Poulin JF, Andres-Enguix I, Simoneau M, Gupta N, Boisvert K, Lafreniere F, McLaughlan S, Dube MP, Marcinkiewicz MM, Ramagopalan $\mathrm{S}$, Ansorge $\mathrm{O}$, Brais B, Sequeiros J, Pereira-Monteiro JM, Griffiths LR, Tucker SJ, Ebers G, Rouleau GA (2010) A dominant-negative mutation in the TRESK potassium channel is linked to familial migraine with aura. Nat Med 16(10): 1157-60. doi:10.1038/nm.2216

35. Nau C, Vogel W, Hempelmann G, Brau ME (1999) Stereoselectivity of bupivacaine in local anesthetic-sensitive ion channels of peripheral nerve. Anesthesiology 91(3):786-95

36. Patel AJ, Honore E (2001) Properties and modulation of mammalian 2P domain $\mathrm{K}+$ channels. Trends Neurosci 24(6):339-46

37. Patel AJ, Honore E, Lesage F, Fink M, Romey G, Lazdunski M (1999) Inhalational anesthetics activate two-pore-domain background $\mathrm{K}+$ channels. Nat Neurosci 2(5):422-6

38. Plant LD (2012) A role for K2P Channels in the operation of somatosensory nociceptors. Front Mol Neurosci 5:21. doi:10.3389/ fnmol.2012.00021

39. Poliak S, Peles E (2003) The local differentiation of myelinated axons at nodes of Ranvier. Nat Rev Neurosci 4(12):968-80

40. Poliak S, Salomon D, Elhanany H, Sabanay H, Kiernan B, Pevny L, Stewart CL, Xu X, Chiu SY, Shrager P, Furley AJ, Peles E (2003) Juxtaparanodal clustering of Shaker-like K+ channels in myelinated axons depends on Caspr2 and TAG-1. J Cell Biol 162(6):1149-60

41. Rasband MN, Trimmer JS, Peles E, Levinson SR, Shrager P (1999) $\mathrm{K}+$ channel distribution and clustering in developing and hypomyelinated axons of the optic nerve. J Neurocytol 28(4-5): 319-31

42. Rhodes KJ, Monaghan MM, Barrezueta NX, Nawoschik S, BekeleArcuri Z, Matos MF, Nakahira K, Schechter LE, Trimmer JS (1996) Voltage-gated $\mathrm{K}+$ channel beta subunits: expression and distribution of Kv beta 1 and Kv beta 2 in adult rat brain. J Neurosci 16(16):484660 
43. Schmidt C, Wiedmann F, Schweizer PA, Katus HA (2014) Thomas, inhibition of cardiac two-pore-domain $\mathrm{K}(+)(\mathrm{K} 2 \mathrm{P})$ channels - an emerging antiarrhythmic concept. Eur J Pharmacol 738:250-5. doi: 10.1016/j.ejphar.2014.05.056

44. Schwarz JR, Eikhof G (1987) Na currents and action potentials in rat myelinated nerve fibres at 20 and 37 degrees C. Pflugers Arch 409(6):569-77

45. Schwarz JR, Glassmeier G, Cooper EC, Kao TC, Nodera H, Tabuena D, Kaji R, Bostock H (2006) KCNQ channels mediate IKs, a slow $\mathrm{K}+$ current regulating excitability in the rat node of Ranvier. J Physiol 573(1):17-34. doi:10.1113/jphysiol. 2006.106815

46. Spencer AN, Przysiezniak J, Acosta-Urquidi J, Basarsky TA (1989) Presynaptic spike broadening reduces junctional potential amplitude. Nature 340(6235):636-8
47. Thomas P, Smart TG (2005) HEK293 cell line: a vehicle for the expression of recombinant proteins. J Pharmacol Toxicol Methods 51(3): 187-200

48. Vabnick I, Trimmer JS, Schwarz TL, Levinson SR, Risal D, Shrager P (1999) Dynamic potassium channel distributions during axonal development prevent aberrant firing patterns. J Neurosci 19(2):747-58

49. Wang H, Kunkel DD, Martin TM, Schwartzkroin PA, Tempel BL (1993) Heteromultimeric $\mathrm{K}+$ channels in terminal and juxtaparanodal regions of neurons. Nature 365(6441):75-9

50. Waxman SG, Ritchie JM (1985) Organization of ion channels in the myelinated nerve fiber. Science 228(4707):1502-7

51. Westphalen RI, Krivitski M, Amarosa A, Guy N, Hemmings HC Jr (2007) Reduced inhibition of cortical glutamate and GABA release by halothane in mice lacking the $\mathrm{K}+$ channel, TREK-1. Br J Pharmacol 152(6):939-45 